\title{
RELAÇÃO ENTRE A DIDÁTICA PROFISSIONAL E A ENGENHARIA DIDÁTICA DE DESENVOLVIMENTO: UMA DISCUSSÃO PARA A FORMAÇÃO DE PROFESSORES DE MATEMÁTICA
}

\author{
RELACIÓN ENTRE DIDÁCTICA PROFESIONAL E INGENIERÍA DIDÁCTICA DEL \\ DESARROLLO: UNA DISCUSIÓN PARA LA FORMACIÓN DE PROFESORES DE \\ MATEMÁTICAS
}

\section{CONNECTION BETWEEN PROFESSIONAL DIDACTICS AND DEVELOPMENT DIDACTIC ENGINEERING: A DISCUSSION FOR THE FORMATION OF MATHEMATICS TEACHERS}

\author{
Francisco Régis Vieira ALVES ${ }^{1}$ \\ Georgyana Gomes CIDRÃO
}

RESUMO: Este trabalho tem por objetivo levar a discussão entre a Engenharia Didática de Desenvolvimento, uma importante metodologia francesa usada por quatro décadas na educação francesa advinda da Didática da Matemática, juntamente com a Didática Profissional, uma vertente francófona que constrói a aprendizagem profissional, visando construir dispositivos para a formação inicial ou continuada de professores, de interesse particular, professores de Matemática. A discussão se baseia no ponto de vista de Chevallard (2009), Pastré, Mayen e Vergnaud (2006), Pastré (2008) e Alves (2018a; 2018b; 2019; 2020). A síntese das pesquisas analisadas mostra que a Didática da Matemática e a Didática Profissional mantém uma linha tênue no que concerne à formação de professores.

PALAVRAS-CHAVE: Didática profissional. Engenharia didática de desenvolvimento. Formação de professores.

RESUMEN: Este trabajo tiene como objetivo liderar la discusión entre la Ingeniería del Desarrollo Didáctico, una importante metodología francesa utilizada durante cuatro décadas en la educación francesa que surge de la Didáctica de las Matemáticas, junto con la Didáctica Profesional, una vertiente francófona que construye el aprendizaje profesional, con el objetivo de construir dispositivos para el inicial. o formación continua de profesores, de especial interés, profesores de matemáticas. La discusión se basa en el punto de vista de Chevallard (2009), Pastré, Mayen y Vergnaud (2006), Pastré (2008) y Alves (2018a; 2018b; 2019; 2020). La sintesis de las investigaciones analizadas muestra que Didáctica de las Matemáticas y Didáctica Profesional, mantiene una tenue línea en lo que concierne a la formación de profesores.

PALABRAS CLAVE: Didáctica profesional. Ingeniería didáctica del desarrollo. Formación de profesores.

\footnotetext{
${ }^{1}$ Instituto Federal de Educação, Ciência e Tecnologia no Ceará (IFCE), Fortaleza - CE - Brasil. Coordenador do Doutorado RENOEN - Polo IFCE. Doutorado em Educação (UFC). Bolsista de Produtividade em Pesquisa do CNPq - Nível 2. ORCID: https://orcid.org/0000-0003-3710-1561.E-mail: fregis@ifce.edu.br

${ }^{2}$ Instituto Federal de Educação, Ciência e Tecnologia no Ceará (IFCE), Fortaleza - CE - Brasil. Mestrado pelo Programa de Pós-Graduação em Ensino de Ciências e Matemática. ORCID: https://orcid.org/0000-0002-44015904. E-mail: georgyanacidrao28@gmail.com
} 
ABSTRACT: This work aims to lead the discussion between Didactic Development Engineering, an important French methodology used for four decades in French education arising from Didactics of Mathematics, along with Professional Didactics, a francophone strand that builds professional learning, aiming build devices for the initial or continuing education of teachers, of particular interest, mathematics teachers. The discussion is based on the point of view of Chevallard (2009), Pastré, Mayen and Vergnaud (2006), Pastré (2008) and Alves (2018a; 2018b; 2019; 2020). The synthesis of the analyzed researches shows that Didactics of Mathematics and Professional Didactics, maintains a tenuous line in what concerns the formation of teachers.

KEYWORDS: Professional didactics. Development didactic engineering. Teacher training.

\section{Introdução}

Pelos compêndios investigativos acerca da Didática da Matemática de origem francesa é que inicialmente vamos compreender a Engenharia Didática e sua evolução no campo da Educação e do Ensino, e como a Didática Profissional tomou espaço atualmente no que se concerne à formação profissional do professor; em caso particular, tomamos o profissional de Matemática.

No Brasil, as teorias que compõem a Didática da Matemática têm se adequado na Educação Matemática usadas na formação de professores (ALVES, 2011). As teorias surgiram nas décadas de 1970 e 1980, levando em consideração o ensino-aprendizagemformação, definidas como: Engenharia Didática, Teoria das Situações Didáticas, Teoria dos Campos Conceituais.

$\mathrm{Na}$ França, após mudanças na pedagogia taylorista do trabalho, a lei Delors garantiu uma melhor qualificação na formação para diversos profissionais, incluindo os professores; todavia, a Engenharia Didática e a Teoria das Situações Didáticas na década de 90 não garantiam a qualificação profisssional aos professores.

Chevallard (2009) comenta que a Engenharia Didática passou a ser usada de outra forma, como propugnava Brousseau (1986), cabendo a necessidade do uso da Engenharia Didática Profissional ${ }^{3}$ para a formação de professores, sendo uma urgência seu uso nos ambientes de formação.

Portanto, partindo do pressuposto que as teorias educacionais francesas têm contribuído bastante para o quadro de formação de professores, observamos que a Engenharia Didática reformulou seus paradigmas formativos na Escola de Verão Francesa em 2009, voltando-se para a tríade: formação-pesquisa-ensino (PERRIN-GLORIAN, 2011; TEMPIER,

\footnotetext{
${ }^{3}$ De mesmo significado Didática Profissional.
} 
2016). Ao mesmo tempo, a Didática Profissional tem levado para os locais de formação excelentes observações e explicações sobre o contexto de formação no trabalho (PASTRÉ; MAYEN; VERGNAUD, 2006; PASTRÉ, 2011).

O artigo traz um itinerário histórico e complementar entre a Engenharia Didática no contexto de sua evolução durante quase quatro décadas de existência, e uma relação com a Didática Profissional, por apresentar um quadro teórico completo para o professor compreender o modus operandi nas situações didáticas profissionais, de acordo com o ponto de vista de Chevallard (2009), Pastré, Mayen e Vergnaud (2006), Pastré (2008), Alves (2018a; 2018b; 2019; 2020).

A síntese das pesquisas analisadas mostra que a Didática da Matemática e a Didática Profissional mantêm uma linha tênue no que se concerne à formação de professores. Após uma série de evoluções, a Engenharia Didática indica um segundo nível para estudar a adaptabilidade das situações ao ensino regular, voltada para a formação de professores que ensinam matemática (TEMPIER, 2016), definida como Engenharia Didática de Desenvolvimento; de mesmo modo, a Didática Profissional centrou-se recentemente na formação do professor usando os pressupostos da ergonomia francesa, na análise do trabalho (PASTRÉ, 2011).

\section{Didática da Matemática no contexto da formação do professor}

$\mathrm{Na}$ década de 1920 o ensino de Matemática era tomado pelo movimento Bourbaki ${ }^{4}$, que ponderava a disseminação da teoria dos conjuntos nos currículos do ensino de matemática. Posteriormente, após a Segunda Guerra Mundial, ocorreu um aprofundamento no conhecimento científico, vindo a reformular o currículo da matemática (LOPES, 1994).

Com isso, as décadas de 1960 e 1960 foram marcadas pelo Movimento da Matemática Moderna (MMM), tendo como principal característica a abordagem dos conceitos da matemática abstrata, como: pensamento axiomático, alto grau de abstração, maior rigor lógico, método dedutivo, entre outros, mantendo um forte vínculo com o modelo estruturalista (PINTO; ALMEIDA; DINIZ, 2007).

Em contrapartida, Piaget (1975) teceu alguns comentários sobre o MMM usando como modelo sua teoria psicogenética, "[...] uma criança não é capaz de raciocinar a partir de hipóteses puras expressas verbalmente, e têm necessidade, para poder realizar uma dedução coerente, de aplicá-las a objetos manipuláveis" (PIAGET, 1975, p. 15). A partir de

${ }^{4}$ Abreviado de Nicolas Bourbaki, nome pseudônimo para um grupo de matemáticos franceses: Cláudio Weil, Claude Chevalley, Henri Cartan entre outros. 
concepções como essas, o MMM obteve um desfecho pautado no insucesso pelo não cumprimento de seus objetivos.

Diante do cenário de mudanças na década de 1980, emergiu a Didática das Disciplinas (ou Didática das Ciências), um agrupamento de teorias pautadas na relação das Ciências (Matemática, Química, Biologia e Física). Contudo, a partir do Centro Observatório e Pesquisa em Ensino de Matemática (COREM), na França, algumas teorias importantes foram surgindo através da Didática da Matemática (DM):

Brousseau quis propor um modelo teórico que contribuísse com a aprendizagem matemática dos alunos (de diversos níveis de escolaridade), compreendendo a aprendizagem como um processo de construção do conhecimento, à luz da teoria piagetiana. Cabe aqui uma breve observação: apesar de Piaget atribuir importância às interações, esse não é o centro da psicologia genética, já a TSD considera fundamental as interações entre sujeitos e atribui papel primordial ao professor como mediador do processo de aprendizagem (BITTAR, 2017, p. 22).

Bem como, “[...] a educação matemática na França foi construída sobre o reconhecimento da necessidade de desenvolvimento de estruturas teóricas específicas" (ARTIGUE, 2002, p. 60). Nesse contexto, no início da década de 1980, três teorias já estavam bem desenvolvidas na Didática da Matemática francesa: Teoria das Situações Didáticas (BROUSSEAU, 1986), Teoria dos Campos Conceituais (VERGNAUD, 1990) e Engenharia Didática (ARTIGUE, 1991).

Considerando tais teorias, destacamos a Engenharia Didática: a premissa é que desde o início estava empenhada nas relações entre pesquisa e ação didática em sistemas educacionais e, como instrumento de desenvolvimento, passou a atribuir um papel às produções de pesquisa em relação ao conhecimento teórico e conhecimento prático. Por isso, a ED manteve uma preferência entre os educadores franceses durante a década de 1980 (PERRINGLORIAN, 2011).

Contudo, a ED é denominada como uma metodologia de pesquisa, desenvolvida a partir de quatro fases (ou etapas), consistindo em: i) análise prévia (ou análise preliminar), ii) concepção e análise a priori, iii) experimentação e iv) análise à posteriori e validação interna/ externa.

$\mathrm{Na}$ primeira fase, entende-se pela análise prévia, que visa uma epistemologia histórica do conteúdo matemático nos moldes atuais do ensino, das concepções dos alunos e obstáculos enfrentados e evoluções diante dos obstáculos, de acordo com objetivos da pesquisa e o estudo da transposição didática (ARTIGUE, 1998). 
Na segunda fase, tem-se a construção e análise a priori, sendo caracterizada pelas variáveis didáticas que Artigue (1998) dispõe como: i) macrodidáticas e ii) microdidáticas, a i) relativas à organização global, ii) relativas à organização de uma sessão ou fase. Além disso, na análise a priori deve-se:

Descrever as escolhas das variáveis locais e as características da situação adidática desenvolvida. • Analisar a importância dessa situação para o aluno e, em particular, em função das possibilidades de ações e escolhas para construção de estratégias, tomadas de decisões, controle e validação que o aluno terá. As ações do aluno são vistas no funcionamento quase isolado do professor, que, sendo o mediador no processo, organiza a situação de aprendizagem de forma a tornar o aluno responsável por sua aprendizagem; • Prever comportamentos possíveis e tentar mostrar como a análise feita permite controlar seu sentido, assegurando que os comportamentos esperados, se e quando eles intervêm, resultam do desenvolvimento do conhecimento visado pela aprendizagem (ALMOULOUD; COUTINHO, 2008, p. 67).

$\mathrm{Na}$ terceira fase tem-se a experimentação, momento de colocar o funcionamento de todo o dispositivo construído, podendo ocorrer correções caso precisar no que concerne às análises locais, implicando um retorno na fase anterior (análise a priori). Nessa fase, são recolhidos os dados obtidos durante a realização das sessões de ensino nas respectivas produções dos alunos em sala de aula ou não (ARTIGUE, 1998).

A última fase é caracterizada pela análise a posteriori e validação, sendo consequência do resultado da experimentação, na exploração dos dados recolhidos para contribuir nos conhecimentos didáticos para a transmissão do saber. Diante disso, nesta fase, entende-se que o resultado da fase anterior é usado para a coleta de dados. Posteriormente, a partir da análise dos dados o processo da validação cessa, podendo ela ser de dois tipos: validação interna e validação externa. A validação interna é "[...] baseada no confronto entre uma análise a priori e uma análise a posteriori" (ARTIGUE, 2002, p. 63), sendo de modo oposto à validação externa, baseada na comparação do desempenho de grupos experimentais e de controle de classes (ARTIGUE, 2002).

Em contrapartida, na França, diante de uma preocupação com uma formação qualificada, a educação francesa ficou marcada por políticas de orientação de qualidade voltada à formação de adultos. Em 1971, a lei Delors foi estabelecida no campo de formação profissional de adultos (CHAMPY-REMOUSSENARD, 2005).

Na França, a rede semântica "formação de adultos" deve datar nos anos 1960; falava-se facilmente, então, de educação permanente. As pessoas que trabalhavam nesse setor tinham vontade de marcar sua especificidade em 
relação à educação em geral e, mais particularmente, em relação ao ensino (BÔAS, 2012, p. 263).

A formação de adultos foi constituindo-se gradativamente no decorrer dos séculos XX e XXI; proeminentemente, duas circunstâncias contribuíram para a formação dos adultos na França: a primeira está no período pós Segunda Guerra Mundial, em 1945, e mais adiante na década de 70, pela evolução das relações sociais, e pela cobrança do campo industrial por uma formação com qualidade diante dos operários.

No período taylorista era comum a competência estar atrelada ao saber-fazer; em outras palavras, os operários não precisavam usar a inteligência nas situações de trabalho, com isso, diante do novo contexto, houve a necessidade de uma melhor formação para os adultos (funcionários) no âmbito industrial.

No entanto, a formação de adultos e formação de professores não é igual, como afirma Bôas (2012) ao dizer que o sistema educativo não tem como objetivo a atividade, mas sim, o saber, de modo específico à didática, ao contrário da formação de adultos que pondera a atividade.

Nesse cenário de mudanças, na década de 90, surge a Didática Profissional (DP), uma vertente que pretende analisar a atividade para a formação de competências profissionais. Pastré, Mayen e Vergnaud (2006) discutem quem a DP é sustentada por arcabouço teórico e prático vindo da psicologia ergonômica, psicologia do desenvolvimento, didática das disciplinas e formação profissional contínua.

\section{Didática Profissional e Engenharia Didática de Desenvolvimento}

A Didática Profissional (DP) foi instaurada pós-período taylorista-fordista, tendo aparição pela primeira vez por Pastré em 1992 em sua tese, sendo definida como uma vertente para formação profissional de adultos. Os seus fundamentos epistemológicos abarcam um conjunto de correntes já supracitados, mas, especificando:

- Conceituação em ação oriunda da psicologia do desenvolvimento, socioconstrutivismo e Teoria dos Campos Conceituais (PIAGET, 1974; VYGOTSKI 1986; VERGNAUD, 1990);

- Psicologia Ergonômica oriunda da Psicologia do trabalho, Análise do trabalho e Ergonomia francesa (FAVERGE, 1972; LEPLAT, 2006);

- $\quad$ Didática das Disciplinas (BROUSSEAU, 1986; VERGNAUD, 1990); 
- $\quad$ Engenharia de Formação e treinamento em adultos.

É importante salientar que a DP no início ponderava as atividades de trabalho dos operários, e atualmente a DP foi estendida para as atividades de ensino. Um dos trabalhos que explica mais profundamente sobre a DP é "La didactique professionnelle" de Pastré, Mayen e Vergnaud (2006); neste trabalho é explicado como essa vertente surgiu e o decorrer do seu desenvolvimento.

A DP é fruto da engenharia de formação e da educação continuada, sendo constituída por um campo de práticas analisadas que deram origem à engenharia didática profissional, uma vertente que utiliza a análise do trabalho para construir dispositivos de formação visando à competência profissional.

A DP é marcada pelo período pós taylorista, em que a formação profissional passou a ser discutida na França, ocasionando uma inovação tecnológica que demandou conhecimento e experiência dos operários. Diante desse contexto, as contribuições da análise ergonômica do trabalho e da psicologia da cognição foram relevantes para o desenvolvimento da DP. O Quadro 1 apresenta conceitos importantes dessa vertente.

Quadro 1 - Elementos importantes que marcam a DP

\begin{tabular}{|c|l|}
\hline Noção ou conceito & \multicolumn{1}{|c|}{ Definição } \\
\hline Taylorismo & $\begin{array}{l}\text { Uma vez que o taylorismo é sobre a organização do } \\
\text { trabalho (PASTRÉ, 2001). }\end{array}$ \\
\hline Construtivismo & $\begin{array}{l}\text { Abordagem que afirma a capacidade inerente do } \\
\text { indivíduo de construir seu conhecimento pela } \\
\text { reestruturação conceituada de suas experiências } \\
\text { acumuladas (VERGNAUD, 2000). }\end{array}$ \\
\hline Atividade & $\begin{array}{l}\text { Qualquer ação contextualizada que mobiliza os } \\
\text { recursos sociocognitivos do indivíduo e pode gerar } \\
\text { aprendizagem (LEPLAT, 1980). }\end{array}$ \\
\hline Competência & $\begin{array}{l}\text { Competência é a mobilização ou ativação de vários } \\
\text { conhecimentos, em uma dada situação e contexto. } \\
\text { Competência é a capacidade de agir em uma situação. } \\
\text { praticado em contextos (pessoais, sociais, } \\
\text { profissional). Diz respeito à realização de tarefas } \\
\text { complexas (resolução problemas, tomada de decisão, } \\
\text { realização de projeto) (LE BOTERF, 2003). }\end{array}$ \\
\hline
\end{tabular}

Fonte: Elaborado pelos autores

A DP nasceu entre esses eixos abordados, refundando na conceituação em ação, psicologia ergonômica, didática das disciplinas e engenharia de formação. A conceituação em ação é oriunda do trabalho de Vergnaud (1990), no que se concerne aos esquemas operatórios 
usados durante as situações profissionais. O trabalho do psicólogo do trabalho Leplat (2013) na distinção entre a tarefa prescrita e atividade real foi importante para o sujeito compreender a análise do trabalho.

O ponto crucial de destaque da DP está na oposição dela com a didática das disciplinas, em específico com a DM, baseado nas pesquisas de Brousseau (1986; 1998), que se concentrava nos alunos, não abarcando a atividade de trabalho do professor.

Pastré (2008) afirma que a TSD se concentra na aprendizagem vinda do saber acadêmico e nas situações didáticas, sendo que a DP tem como principal objetivo as situações de trabalho profissional e a aprendizagem vinda da ação do trabalho, que ele chama de conhecimento pragmático, principalmente situações complexas em que o trabalhador move uma inteligência operativa para se sobressair, mostrando uma habilidade que recai na sua competência de gerir situações incomuns de trabalho.

Pastré (1992) admite que antes da criação da DP, quando ainda estava supervisionando o trabalho dos mineiros na engenharia de formação, ele sempre parava na análise do trabalho, e essa análise foi crucial para a criação dessa vertente. $\mathrm{O}$ autor concluiu que se o operário analisar sua atividade, certamente ele melhorará sua competência.

De início a DP se concentrava na análise de trabalho industrial, todavia, na última década, tem se interessado em analisar a atividade de demais profissões, incluindo a atividade de ensino de professores, devido à procura das Ciências em Educação na DP para a compreensão da atividade real dos professores em formação inicial ou continuada (PASTRÉ; MAYEN; VERGNAUD, 2006; VINATIER, 2013).

No Brasil, a DP tem um quadro bem recente nas pesquisas científicas, no entanto, os trabalhos de Alves $(2018 \mathrm{a} ; 2018 \mathrm{~b} ; 2019 ; 2020)$ tem se destacado pioneiramente na formação de professores de matemática. Esse autor tem estendido alguns termos da TSD para a atividade profissional de professores de Matemática; os trabalhos mostram um complemento entre a DP e a TSD, bem como alguns planos de competência diante de três elementos: alunos, colegas de trabalho e normas institucionais.

Além disso, Baudouin (1999) propõe uma diferença entre os pressupostos da DP e da TSD conforme a Figura 1: este autor diz que o triângulo didático (aluno-professor-saber) é insuficiente para analisar a atividade do professor.

Figura 1 - Tetraedro que exibe a Didática Profissional para análise da atividade do professor 


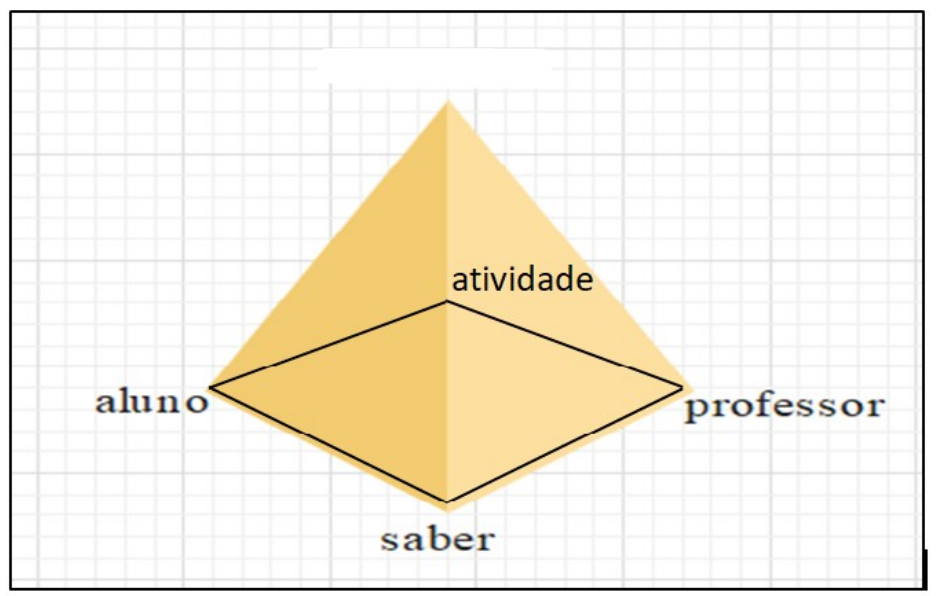

Fonte: Adaptado de Baudouin (1999)

Por essa figura tridimensional, Baudouin (1999) conclui que a lógica dos modelos de saberes científico como a TSD propõe não é suficiente para explicar as situações de trabalho incomuns que os professores tendem a encontrar no meio profissional. Diante disso, Chevallard (2009), assume que houve uma negligência por parte das pesquisas dos didatas da matemática, “[...] adiamos o cuidado de repensar o ato didático, voltado para adultos no trabalho, com referência ao desenvolvimento das habilidades e experiência no trabalho" (CHEVALLARD, 2009, p. 9).

Chevallard (2009) discorre que após a explosão da formação dos adultos na formação profissional contínua no final da década de 80 , a DM foi tendo outros itinerários de pesquisa, “[...] a metodologia de engenharia didática está sendo usada em sentidos diferentes daquele entendido por Brousseau, inclusive por alguns dos pesquisadores da Didática da Matemática, havendo a necessidade do uso da Didática Profissional" (CHEVALLARD, 2009, p. 41), o cenário de formação e competência com viés profissional tomou destaque diante da DP.

Desde a década de 1990 a DM já pensava em estratégias de formação para o professor. Mas, somente em 2009, na XV ${ }^{\text {a }}$ Escola de Verão em Didática da Matemática (do francês, École d'été de Didactique des Mathématiques), ocorrida na França, Perrin-Glorian abre espaço para a Engenharia Didática de Desenvolvimento, voltada para a formação de professores (PERRIN-GLORIAN; BELLEMAIN, 2009).

Diante de Perrin-Glorian (2011, p. 24): “[...] a engenharia didática não é um objeto acabado, mas um objeto cujo design deve ser capaz de continuar em uso", contudo, “[...] a formação do professor é um fenômeno relativamente novo na comunidade de pesquisadores em didática" (VERGNAUD, 1992, p. 23). 
Após uma série de mudanças na formação de adultos, a ED tomou como princípio a formação de professores de Matemática, sendo definida como Engenharia Didática de Desenvolvimento. Perrin-Glorian (2009) conclui que existem três condições para a realização de uma EDD:

i) Deixar determinada liberdade de ação ao professor: esta condição já é válida no primeiro nível, mas agora trata-se de definir a sequência de situações com o professor e analisar como ele adapta o documento que lhe é fornecido.

ii) Utilizando os documentos produzidos, os professores devem procurar não reproduzir a história, mas as condições da aprendizagem, a questão essencial para a engenharia didática, sendo como identificar os elementos essenciais para a realização efetiva da atividade.

iii) É necessário apoiar-se em uma engenharia didática de primeira geração que possibilite a construção de uma situação fundamental e sua análise.

Mesmo que alguns invariantes permaneçam, a engenharia didática tornou-se uma teoria válida para a comunidade de pesquisadores e professores que tomam o ensino e a aprendizagem como variantes importantes para a sala de aula.

\section{Competência Profissional do professor}

O termo competência passou a ser difundido no final da década de 1960 , sendo observada como um conjunto de saberes: saber-fazer, saber científico, saber em ação (GILLET, 1991). De tal modo, a competência passou a ser instaurada nas indústrias na década de 1970 na França, tendo uma forte relação com o desempenho no trabalho; posteriormente, houve um rompimento estrutural do trabalho com a pedagogia tayloriana.

Com isso, a organização do trabalho se torna o coração da competência, outrossim, a competência está entrelaçada com o saber agir e reagir em uma determinada situação de trabalho em que o indivíduo consiga implementar práticas profissionais para resolver problemas advindos das situações novas de trabalho, como Pastré (2004, p. 217) define:

A habilidade de um operador, se ele é um operador de máquina ou um viticultor, obviamente, não reduz ao domínio da estrutura conceitual da situação. Mas esta é a chave para o sentido da competência, em torno da qual irá organizar-se de forma hierárquica segundo suas habilidades, procedimentos, gerenciamento e recursos, etc. A identificação da estrutura 
conceitual de uma classe de situações profissionais correspondem à dimensão cognitiva das habilidades.

A DP leva em consideração o desenvolvimento de habilidades de treinamento, estando no centro de suas preocupações. Corroboramos com Pastré (1999, p. 403), ao dizer que a epistemologia da DP “[...] vem no âmbito da produção de recursos educacionais contendo situações de trabalho que servem de suporte para a formação e desenvolvimento de habilidades profissionais".

A DP tem princípios paralelos ao behaviorismo, em que a competência (reunião de habilidades) se mostrava no desempenho exitoso de uma função trabalhista. Em oposição, Pastré (2011) diz que a competência não deve ser medida diante de um bom desempenho da atividade, mas a competência deve se mostrar diante de uma situação nova de trabalho.

Além disso, tomamos a seguinte indagação: como um trabalhador toma sua profissionalização? Com isso, Vergnaud (2001, p. 2) define um profissional competente em:

1 - A é mais competente que B, se souber fazer algo que B não pode fazer;

2 - A é mais competente que B, se o fizer de uma maneira melhor. A melhor comparação pressupõe critérios complementares (velocidade, confiabilidade, economia etc);

3 - A é mais competente se tiver um diretório de recursos alternativos que lhe permita usar um procedimento ou outro e, assim, adapta-se mais facilmente a diferentes cenários que possam surgir;

4 - A é mais competente se souber lidar com uma nova situação, de uma categoria nunca antes encontrada.

No entanto, não é suficiente que uma pessoa tenha os recursos (pode-se dizer "habilidades") para "ser" competente: ela deve ser capaz de organizá-los e mobilizá-los em combinações relevantes para gerenciar "situações profissionais" levando em consideração os “critérios de desempenho" relacionados. São esses "critérios de desempenho" que nortearão a construção de combinatória de recursos.

Quando o termo competência invade o ofício do professor, fica evidente que não é fácil gerenciar as situações de trabalho em sala de aula. No entanto, Pastré, Mayen e Vergnaud (2006) apontam que devido à procura de respostas, alguns pesquisadores em Ciência da Educação procuraram a ergonomia para analisarem o trabalho do professor. 
Com isso, notamos que o quadro da Didática Profissional elenca contribuições para a prática dos professores (professores de Matemática), voltadas para uma evolução e desenvolvimento de habilidades no trabalho.

Em sala de aula, a competência profissional do professor de Matemática está atrelada às habilidades nas tarefas cotidianas exercidas em torno da profissão no processo de aprendizagem no trabalho. Portanto, Alves e Catarino (2019) assumem a existência de três categorias ou níveis, que gerenciam a aprendizagem do professor de Matemática, mediante as situações profissionais. Assim, as atividades profissionais do professor de Matemática devem atender aos planos de níveis: “(i) plano da sala de aula, (ii) plano do posto de trabalho, (iii) o plano geral da instituição de ensino, ou instituição escolar" (ALVES; CATARINO, 2019, p. $115)$.

O plano (i) (sala de aula) analisa a atividade docente tendo múltiplos propósitos, embutidos uns nos outros. Um objetivo que o professor deve ter é ter calma na sua classe (a disciplina) de modo a poder pôr os alunos para trabalhar; em seguinte, o professor deve provocar aprendizagens, finalizando com o desenvolvimento cognitivo de seus alunos.

No plano (ii), apresentamos a competência profissional do professor através do campo político e da negociação social classista. Nesse nível, de modo pormenorizado, procuramos observar a evolução do professor de Matemática, especificamente no trabalho. Pastré (1999) recordar-nos que a avaliação de um indivíduo no posto de trabalho não se dá perante um sistema de qualificação. Desse modo, o trabalho do professor não deve ser avaliado na tarefa prescrita, mas sim, o trabalho realizado na instituição.

No plano (iii) a competência está vinculada ao modo cognitivista. A partir dos modelos socioconstruvistas e do construtivismo acentuado nos campos conceituais, a competência dos adultos é perspectivada no local de trabalho, passando a aprenderem no lócus de trabalho. Sendo assim, “[...] a competência profissional do professor se consubstancia por uma passagem progressiva e a coordenação das atividades de ação e de antecipação, construção e reconstrução de esquemas cognitivos, estruturados hierarquicamente por invariantes operatórios" (ALVES; JUCÁ, 2019, p. 12).

Sabemos que a conceituação antecede a ação, por esse motivo, a cognição vem antes de operarmos quaisquer ações. A partir desse pressuposto piagetiano, percebemos que a competência desenvolve a aprendizagem do professor no trabalho. A competência é um processo de aquisição de conhecimento e de ação profissional: o indivíduo utiliza o conhecimento para aprimorar sua competência. Temos que o núcleo fundamental e 
estruturante de um ofício está no modo de aprender nas situações que o trabalho desenvolve durante a ação do operário.

Portanto, o professor aprende por meio da prática no trabalho, agindo por um repertório de ações típicas do seu posto de trabalho, descritas por um regime de manuais normativos e oficiais que controlam a ação. Assim, a competência será organizada por um conjunto de habilidades, enfáticas em regras nem sempre explícitas, mas circunstanciadas e pragmáticas.

$\mathrm{Na}$ atividade profissional do professor de Matemática, os conceitos pragmáticos fazem parte da aprendizagem no trabalho. Sabemos que a competência não é atrelada somente aos conhecimentos epistêmicos, mas sim, está no âmago do pragmatismo. Pastré (2002) endereça as principais características do pragmatismo no trabalho, que também se estende para a atividade do professor de Matemática.

\section{Considerações finais}

A DM tem uma longa tradição na Educação Matemática, no que concerne ao ensino, aprendizagem e formação de professores, sendo um conjunto de teorias que levam aperfeiçoamento à formação de professores e melhorias nas condições para o ensino e aprendizagem discente. Contudo, não podemos negligenciar que a TSD e ED não fornecem um contexto completo no que se concerne às situações de trabalho, requerendo uma complementariedade com a DP para avaliar a atividade de ensino profissional dos professores de Matemática.

Diante desse espaço, os compêndios complementares entre DM e a da DP se mostram como relevantes no quadro de formação de professores, em especial aos professores de Matemática. Considera-se que as vertentes de origem francófonas têm se ampliado pela Europa e América, principalmente no Brasil. A ED e TSD são recorrentes em pesquisas científicas na parte de Educação e Ensino de Matemática, no entanto, a DP ainda é nova no cenário de pesquisas brasileiras.

No entanto, alguns trabalhos têm se destacado em pesquisas nacionais de modo inovador no que se concerne à complementariedade entre essas vertentes para a formação de professores no Brasil; ficou nítido que essa relação entre as teorias ${ }^{5}$ é relevante para a compreensão no contexto de formação inicial ou continuada em relação à competência

\footnotetext{
${ }^{5}$ Didática Profissional é uma teoria de ensino profissional; Teoria das Situações Didáticas é uma teoria de ensino; Engenharia Didática é uma metodologia de pesquisa.
} 
profissional, situações didáticas profissionais, obstáculos profissionais, dentre outros, que ajudam o professor a compreender o trabalho.

Este trabalho tem, portanto, o potencial de mostrar como a DP atualmente se tornou urgência, nos moldes de formação dos adultos, diante do quadro de mudanças que desde os anos 90 tem proporcionado transformações e evoluções de vertentes na formação de professores, como no caso da ED, que atualmente tem se mostrado uma EDD para a formação e treinamento de professores de Matemática.

Por fim, após um período de formação profissional contínua e pós taylorismo, teóricos apontam que a DP e a DM, diante de uma trajetória de evoluções e modificações, levam um potencial às pós-graduações em nível de mestrado e doutorado na formação de professores, como é caso das Universidades francófonas (Québec, Lyon, Éspé, dentre outras).

AGRADECIMENTOS: Agradecemos o apoio financeiro do Conselho Nacional de Desenvolvimento Científico e Tecnológico (CNPq) para as pesquisas em âmbito educacional desenvolvidas no Instituto Federal de Educação, Ciência e Tecnologia do Ceará.

\section{REFERÊNCIAS}

ALVES, F. R. V. Didática da Matemática: Licenciatura em Matemática. Fortaleza: UAB/IFCE, 2011

ALVES, F. R. V. Didactique des Mathématique (DM) et la Didactique Professionelles (DP): une perspective de complementarité et la formation des enseignants au Brésil. Imagens da Educação, v. 8, n. 3, p. 1-17, 2018 a.

ALVES, F. R. V. Didactique professionnelles (DP): une perspective d'application au travail du professor de mathématiques. REVEMAT, v. 13, n. 2, p. 184-209, 2018 b.

ALVES, F. R. V. A vertente francesa de estudos da didática profissional: implicações para a atividade do professor de matemática. Revista Vydia Educação, n. 39, v. 1, p. 255-275, 2019.

ALVES, F. R. V; CATARINO, P. M. M. C. Situação Didática Profissional: um exemplo de aplicação da Didática Profissional para a pesquisa objetivando a atividade do professor de Matemática no Brasil. Indagatio Didactica. v. 11, n. 1, p. 103-120, 2019.

ALVES, F. R. V; JUCÁ, S. C. S. Trabalho e competência do professor de Matemática: Um ponto de vista a partir da Didática Profissional. Revista Multidisciplinar em Educação, v. 6, n. 14, p. 103-123, 2019. 
ALVES, F. R. V. A Didática Profissional (DP): implicações para a formação do professor e o ensino de disciplinas específicas no Brasil. Revista Ibero-Americana de Estudos em Educação, Araraquara, v. 15, n. 4, p. 1903-1918, 2020.

ARTIGUE, M. Ingénierie Didactique. Recherches em Didactique des Mathématiques, Grenoble: La Pensée Sauvage-Éditions, v. 9.3, p. 281-308, 1998.

ARTIGUE, M. Quelques leçons des ingénieries didactiques. In: GUIN, D.; TROUCHE, L. (Eds.). L'instrumentation de calculatrices symboliques: um problems didactique. Grenoble: La pensée sauvage, 2002.

ARTIGUE, M. L'ingénierie didactique comme thème d'étude. In: En amont et en aval des ingénieries didactiques: XVe École d'Été de didactique des mathématiques; ClermontFerrand - août 2009. Grenoble: La Pensée Sauvage, 2011. v. 1, p. 15-25.

BAUDOUIN, J. M. La competénce et le théme de l'acitivité: vers une nouvelle conceptualization didactique de la formation. Raison educative, v. 2, n. 2, p. 149-168, 1999.

BITTAR, M. Contribuições da teoria das situações didáticas e da engenharia didática para discutir o ensino de Matemática. In: TELES, R. A. M.; BORBA, R. E. S. R, MONTEIRO, C. E. F. (org.). Investigações em Didática da Matemática. Editora UFPE, 2017.

BÔAS, L. V. Formação de adultos, formação de professores? Entrevista com Jean-Marrie Barbier. Educação \& Linguagem, v. 15, n. 2, p. 259-268, 2012.

BROUSSEAU, G. Fondements et méthodes de la didactique des mathématiques. Recherches em Didactique des Mathématiques, Grenoble, v. 7, n. 2, p. 33-116, 1986.

BROUSSEAU, G. Didactique des sciences et formation des professeurs. In: COMITI, C. et al. Guillaud. Didactique des disciplines scientifiques et formation des enseignants. Hà Nội: Maison d'Edition de l'Education Giáo dục, 1996. p.19-34.

BROUSSEAU, G. Théorie des situations didactiques. In: BALACHEFF, N. Grenoble: La Pensée Sauvage. (Recueil de textes de didactique des mathématiques 1970-1990. 1998.

BROUSSEAU, G. Premières notes sur 1'observation des pratiques de classes. Journée VISA, INRP, 2008.

CHAMPY-REMOUSSENARD P. Les théories de l'activité entre travail et formation. Savoirs, n. 8, p. 9-50, 2005.

CHEVALLARD, Y. La notion d'ingénierie didactique, un concept à refonder. Questionnement et élémentos de réponses à partir de la TAD. In: MARGOLINAS, C. et al. (org.) En amont et en aval des ingénieries didactiques $X V^{a}$ École d'Été de Didactique des Mathématiques - Clermont-Ferrand (Puy-de-Dôme). Recherches em Didactique des Mathématiques, Grenoble: La Pensée Sauvage, v. 1, p. 81-108, 2009.

FAVERGE, J. M. L'analyse du travail, en Traité de Psychologie Appliquée. Presses Universitaires de France, Paris 1972. t. 3. 
GILLET, P. Crie treinamento. Paris: ESF, 1991.

LE BOTERF, G. Desenvolvendo a competência dos profissionais. 3. ed. Porto Alegre: Artmed, 2003.

LEPLAT, J. La psychologie ergonomique. Paris: PUF, 1980.

LEPLAT. J. La notion de régulation dans l'analyse de l'activité. Revue Pistes, v. 8, n. 1, p.1$30,2006$.

LOPES, M. L. M. L. GEPEM - Grupo de Estudos e Pesquisas em Educação Matemática. Em Aberto, Brasília, ano 14, n. 62, abr./jun. 1994.

PASTRÉ, P. Requalification des ouvriers et didactique professionnelle. Education permanente, n. 111, p. 33-54, 1992.

PASTRÉ, P. La conceptualisation dans l'action: bilan et nouvelles perspectives. Education Permanente, Paris, n. 139, p. 13-36, 1999.

PASTRÉ, P; MAYEN, P; VERGNAUD, G. La didactique professionnelle. Revue française de pédagogie, n. 154, p. 145-198, 2006.

PASTRÉ, P. Analyse de l'activité d'apprentissage: le point de vue de la didactique professionnelle. Travail et Apprentissages, n. 2, p. 62-72, 2008.

PASTRÉ, P. L' analyse du travail et didactique profissionnalle. Revue Française de Pédagogie, v. 3, n. 138, pp. 9-17, 2002.

PASTRÉ, P. Les compétence profissionnelles et leur développement, In: Faizon, P. Ergonomie. Paris: PUF, 2004.

PASTRÉ, P. La Didactique Professionelle. Education, Sciences \& Society, v. 2, n. 1, p. 8395, 2011.

PERRIN-GLORIAN, M-J; BELLEMAIN, P. M. B. L'ingénierie didactique a l'interface de la recherche avec l'enseignement. Développement des ressources et formação des enseignants. In: MARGOLINAS, C. et al. (org.). En amont et en aval des ingénieries didactiques, $\mathrm{XV}^{\mathrm{a}}$ École d'Été de Didactique des Mathématiques - Clermont-Ferrand (PUY-de-Dôme).

Recherches em Didactique des Mathématiques, Grenoble: La Pensée Sauvage, v. 1, p. 57 $78,2009$.

PERRIN-GLORIAN, M. J. L'ingenierie didactique a l'interface de la recherche avec l'enseignement. Developpement de ressources et formation des enseignants. In: MARGOLINAS, C. et al. (Eds.) En amont et en aval des ingénieries didactiques. Grenoble: La Pensee Sauvage, 2011. p. 57-78.

PIAGET, J. La représentation du monde chez l'enfant. Paris: PUF, 1974.

PIAGET, J. A teoria de Piaget. In: MUSSEN, P. H. (org.). Psicologia da criança. Desenvolvimento Cognitivo. São Paulo: E.P.U. 1975. v. 4, p. 71-117. 
PINTO, N. B.; ALMEIDA, A. F.; DINIS, M. A. Saberes docentes para o ensino da Matemática Moderna. 2007.

TEMPIER, F. New perspectives for didactical engineering: an example for the development of a resource for teaching decimal number system. Journal of Mathematical Teacher Education, v. 19, n. 1, p. 261-276, 2016.

VERGNAUD, G. La Théorie des champs conceptuels. Recherches em didactique des mathématiques, v. 10, n. 3, p. 133-170, 1990.

VERGNAUD, G. Approches didactiques en formation d'adultes. In: VERGNAUD, G. Éducation Permanente. 1992. n. 11.

VERGNAUD, G. O longo e o curto prazo na aprendizagem da matemática. Educar em Revista, Curitiba, n. esp. 1, p. 15-27, 2001.

VINATIER, I. Le travail enseignant: une approche de didactique professionnelle. Bruxelle, De Boeck, 2013.

VYGOTSKY, L. S. Thought and language (A. Kozulin, Trans.). Cambridge, MA: MIT Press, 1986.

\section{Como referenciar este artigo}

ALVES, F. R. V.; CIDRÃO, G. G. Relação entre a didática profissional e a engenharia didática de desenvolvimento: uma discussão para a formação de professores de matemática. Revista Ibero-Americana de Estudos em Educação, Araraquara, v. 16, n. 3, p. 2083-2099, jul./set. 2021. e-ISSN: 1982-5587. DOI: https://doi.org/10.21723/riaee.v16i3.14883

Submetido em: 25/10/2020

Revisões requeridas em: 18/11/2020

Aprovado em: 11/12/2020

Publicado em: 01/07/2021 